\title{
The Application of HIRARC on Attitude towards Safe Driving Scale (ASDS) according to PreSiM Model
}

\author{
Mohamad Ghazali Masuri', Akehsan Dahlan', Khairil Anuar Md Isa², Rugayah Hashim³ \\ 1 Occupational Therapy Department, ${ }^{2}$ Basic Sciences Department, Faculty of Health Sciences, \\ ${ }^{3}$ Research \& Innovation Division, \\ Universiti Teknologi MARA, Malaysia
}

zalie222@gmail.com akehsan.dahlan@yahoo.com khairil_hpm@hotmail.com guy73106@yahoo.com

Tel: 0196259314

\begin{abstract}
The level of hazard identification (HI) determined based on ASDS mean cut off. The risk assessment (RA) and risk control (RC) later translate into PreSiM model. The process of transformation into the matrix table shows promising result in assessing human factors in term hazard, risk and possible RTA control. This scale will enable the Occupational Safety and Health (OSH) team to evaluate the level of severity and action needed to prevent further injury. However, caution should be made where human components and occupational performance of drivers may change over time, and the risk controls are yet to be further analyzed.
\end{abstract}

Keywords: Human factors; Transportation; HIRARC; ASDS46

eISSN: 2398-4287@ 2020. The Authors. Published for AMER ABRA cE-Bs by e-International Publishing House, Ltd., UK. This is an open access article under the CC BYNC-ND license (http://creativecommons.org/licenses/by-nc-nd/4.0/). Peer-review under responsibility of AMER (Association of Malaysian Environment-Behaviour Researchers), ABRA (Association of Behavioural Researchers on Asians) and cE-Bs (Centre for Environment-Behaviour Studies), Faculty of Architecture, Planning \& Surveying, Universiti Teknologi MARA, Malaysia.

DOI: https://doi.org/10.21834/ebpj.v5i14.2182

\subsection{Introduction}

Improving human mobility from one place to another is the primary function of vehicles or transport (Third African road safety congress, 1997). However, this system arises with a momentous risk. This complex ergo system (human>machine>environment) as proposed by Bridger, (1995) combining with complex activity in the local environment, offers a considerable risk of an accident. According to Alert Driving Magazine, (2011), $90 \%$ of road traffic accidents were caused by human error, which made a human error as a significant ergosystem component. The number of fatality due to a road traffic accident (RTA) worldwide has increased for the past few years, where on average 19.59 people were died in Malaysia every day due to the RTA. Many reports have clearly stated that human factors contributed to up to $97 \%$ of RTA. This scenario creates concern from many agencies, including health care professionals about the fundamental issue of this phenomena. There was considerable public concern about assessment and intervention used by the enforcement body in Malaysia. Due to that, this study believes that establishing proper outcome measure in identifying risk driving behaviour is essential. For the last few years, a group of a researcher under Traffic, Accident and Cognitive Ergonomics (TrACE) interest group has worked on developing assessment tools to measure specific human factors that can be related to safe attitude (Masuri., Mohd Asib, Dahlan \& Md Isa 2019). One of the latest outcomes from this research was the development of the Pre-licensing - Simulation Maintenance (PreSiM) licensing model followed by a psychological assessment tool called Attitude towards Safe Driving Scale (ASDS). The recent study was aware that it is nearly impossible to create single attitude assessment related to driving that fits all due to the complexity of human behaviour including driving activity (Masuri, Md Isa, \& Mohd Tahir, 2012). However, the benefit of the assessment outcome should be highlighted, and perhaps it will create awareness among respondent on how vital to answer all question honestly and as accurate as possible. Indirectly, the questionnaire should motivate the respondent to respond diligently. This study aims to build

eISSN: 2398-4287@ 2020. The Authors. Published for AMER ABRA cE-Bs by e-International Publishing House, Ltd., UK. This is an open access article under the CC BYNC-ND license (http://creativecommons.org/licenses/by-nc-nd/4.0). Peer-review under responsibility of AMER (Association of Malaysian Environment-Behaviour Researchers), ABRA (Association of Behavioural Researchers on Asians) and cE-Bs (Centre for Environment-Behaviour Studies), Faculty of Architecture, Planning \& Surveying, Universiti Teknologi MARA, Malaysia.

DOI: https://doi.org/10.21834/ebpj.v5i14.2182 
a new HIRARC matrix to measure hazard and risk of human factors related to the transportation issue. In order to achieve this aim, this study was highlighted three main objectives as follow 1 ) to define the value of ASDS raw score for each domain into five level of severity (S), 2) to define the value of ASDS domain score into three categories (Low, Medium and High) and, 3) to transform the number 2 objective into three different stages of PreSiM model (Pre, Si and M) which later used to determine the level of likelihood (L).

A recent study of human factors and transportation shows that driving contributes to significant risk and health threat (Masuri, Dahlan, Danis and Isa 2014a, 2014b) however, there was no clear explanation related to hazard identification, risk assessment and potential risk control. Even though risky driving attitude may influence by a secondary factor such as passenger (Abang Mustaffa, Masuri, Dahlan, and Md. Isa 2015), yet this study believe that an individual element is the most substantial influence in driving decision. In a previous study by (Masuri, Dahlan, Danis \& Md Isa, 2016 and 2017) they had explored the psychometric properties of a driver's attitude towards safe driving practice using ASDS46 questionnaire. They also had established PreSiM model as one of the proposed licencing processes in Malaysia. This study transformed the result of ASDS46 into stages of PreSiM model and fitting into the HIRARC matrix.

\subsection{HIRARC integration in PreSiM model}

The term Hazard Identification, Risk Assessment and Risk Control (HIRARC) is a well-established term used in occupational safety and health (OSH) team worldwide. The method of HIRARC generally is a proposed guideline that can be used by employer and employee to establish safety and health program at the workplace. In the current practice of basic risk management, HIRARC has become an essential reference in planning, management and operation. Business who carried out the risk assessment has experienced many changes in their working practice. They also reported positive changes and able to prepare for necessary corrective action. This is a systematic process which should be recorded and analysed. This process is a continuous process of service and safety improvement which should be maintained by the business entity. The implementation of this method is subject to any available process or guideline later developed by the workplace. There was flexibility for us to create a suitable approach that suits the nature of our business. The objectives of HIRARC were; to identify all the factors that may cause harm to a person, to consider what the chances are of that harm befalling anyone in the circumstances of a particular case and the possible consequences that could come from it (the risks) and to enable employers to plan, introduce and monitor preventive measures to ensure that the risks are adequately controlled at all times. This paper was an extension of previous work by (Masuri, Dahlan, Md Isa and Hashim 2020). In the last article had explained the risky and complicated activity of driving (Masuri, Dahlan, Danis \& Md Isa, 2016).

The PreSiM model is a dynamic model that previously proposed for a new licensing process in Malaysia (Masuri, Dahlan, Danis \& Md Isa 2018). This model introduced three control elements, namely; prevention \& screening, rehabilitation, and maintenance. Due to the different demographics of the respondent that fall into each stage, the potential risk may also differ accordingly. For example, highrisk drivers will need to go through the most rigid process where they must go through re-evaluation process and rehabilitation program; this makes them under high likelihood to involve with an accident with more severe risk. This model consists of three stages with different aims and potential diverse participation and level of risk.

The first stage was the pre-screening. This stage aims to assist an individual to screen their personal ability to enrol for a full licensing program. The participant which successful in this stage should be able to understand and identify their readiness to join into the next steps. Individual who take the survey at this stage is considered as low likelihood and low severity of the risk. Minimal control is needed for this group of people. There is a requirement to monitor their current attitude and readiness to take a license. The self-evaluation will give an overview of the potential risk that he or she may experience at the next stage. The other critical step is the maintenance stage. This stage is crucial for drivers with valid driving license. Risky drivers should attend a driving rehabilitation program. For risk control (RC) the rehabilitation stage will involve the following components; driving rehabilitation program, support group, module or exam-based assessment and psychological support. The re-evaluation stage is focusing on the maintenance of ethical and competent drivers. At this stage, each driver was expected to self-re-evaluate their driving performance. A support group may benefit at this stage where it could help to prevent further offences or injury. This stage required re-evaluation of driver's competency level, medical record, family and emotional support and other psychological support. This model has highlighted the importance of monitoring components. It also recommended introducing reassessment and rehabilitation as part of the maintenance process. Even though maintenance may not be able to change driver's behaviour, however, this study believes that excellent screening method and law enforcement will shape better drivers in the future. Any changes could be recorded according to the proposed risk matrix calculator. The driver's competency should be reassessed at any time, and the potential risk must be registered.

\subsection{Method}

This section explained the process of transformation from current risk matrix table into ASDS-PreSiM-HIRARC table (fig 1 to fig 2.). The formula for domain severity matrix later told in table 1. Figure 1 shows an illustration of a risk matrix that commonly used in the process of HIRARC. The uses of likelihood and severity in the qualitative method are presented in this matrix. It is a very effective method to communicate the distribution of risk in the workplace or activity.

\begin{tabular}{|c|c|c|c|c|c|}
\cline { 2 - 6 } \multicolumn{1}{c|}{} & \multicolumn{5}{c|}{ Severity (S) } \\
\hline Likelihood (L) & $\mathbf{1}$ & $\mathbf{2}$ & $\mathbf{3}$ & $\mathbf{4}$ & $\mathbf{5}$ \\
\hline $\mathbf{5}$ & $\mathbf{5}$ & 10 & 15 & 20 & 25 \\
\hline
\end{tabular}




\begin{tabular}{|c|c|c|c|c|c|}
\hline $\mathbf{4}$ & 4 & 8 & 12 & 16 & 20 \\
\hline $\mathbf{3}$ & 3 & 6 & 9 & 12 & 15 \\
\hline $\mathbf{2}$ & 2 & 4 & 6 & 8 & 10 \\
\hline $\mathbf{1}$ & 1 & 2 & 3 & 4 & 5 \\
\hline
\end{tabular}

\section{High risk}

Medium risk

Fig. 1. An illustration of the original risk matrix table score and classification

Figure 2 shows the transformation of ASDS46 domain score into a risk matrix calculator. The likelihood value is depending on the ASDS46 domain score (High, Medium, Low), and it will change according to the stages of PreSiM model with the increment value $=1$. For example, the respondent who took the assessment during the pre-assessment phase, the likelihood score will be equal to 1 for lowrisk drivers, and that makes the $S$ value relatively low. If the respondent ASDS46 domain score maintains at low risk, but at the simulation stage, the number of likelihood will increase to two. This phenomenon will contribute to an increment of a severity score. Finally, if the respondent ASDS46 domain score maintains at low risk but the maintenance stage, the likelihood value will start at three. This will contribute to the significant increment of severity score later. That model may predict a risk factor based on the terminology established (Masuri, Dahlan, Md Isa \& Hashim 2020). For category pre-assessment, it is referring to a group who were not yet registered for the licensing process. Simulation group is referring to a respondent who already registered for licensing, and a last group is a group of active drivers. However, passive drivers with a valid license may fall under category two of PreSiM model. Only two types of respondent who participated in this study pre-assessment and maintenance. The level of severity for each ASDS46 domain explains in table 2. Caution should be made that the risk factor calculation will be on an individual basis. Table 3 demonstrates the difference in term of likelihood (L) and severity (S) level based on two groups of respondent who participated in the pre-assessment and maintenance stage.

\begin{tabular}{|c|c|c|c|c|c|c|c|c|c|c|c|}
\hline & & & & & & & \multicolumn{5}{|c|}{ Severity (S) } \\
\hline \multicolumn{6}{|c|}{ PreSiM stages } & Likelihood (L) & 1 & 2 & 3 & 4 & 5 \\
\hline & & & & \multirow{3}{*}{$\begin{array}{c}\text { M } \\
\text { Maintenance } \\
\text { score }\end{array}$} & High (5) & 5 & 5 & 10 & 15 & 20 & 25 \\
\hline & & \multirow{3}{*}{$\begin{array}{c}\mathbf{S i} \\
\text { Simulation } \\
\text { score }\end{array}$} & High (4) & & $\begin{array}{l}\text { Medium } \\
\text { (4) }\end{array}$ & 4 & 4 & 8 & 12 & 16 & 20 \\
\hline \multirow{3}{*}{$\begin{array}{c}\text { Pre } \\
\text { Pre-assessment } \\
\text { score }\end{array}$} & High (3) & & $\begin{array}{l}\text { Medium } \\
\text { (3) }\end{array}$ & & Low (3) & 3 & 3 & 6 & 9 & 12 & 15 \\
\hline & $\begin{array}{l}\text { Medium } \\
\text { (2) }\end{array}$ & & Low (2) & & & 2 & 2 & 4 & 6 & 8 & 10 \\
\hline & Low (1) & & & & & 1 & 1 & 2 & 3 & 4 & 5 \\
\hline
\end{tabular}

Fig. 2. Transformation of ASDS domains score category into PreSiM model and risk matrix

Table 1 shows the calculation for each domain of ASDS. The score for each severity scores was based on equal distribution of each area minimal and maximum score. For example, a minimal rating for domain 1 is 13 , and the maximum is 65 . The maximum score minus the minimum and divided into five Likert scales (low, mild, moderate, severe and very severe). Once the level of severity was identified for each domain, the relative risk can now be calculated. The risk can be calculated according to this formula $L X S=$ Relative risk. For respondent who takes the assessment during the pre-assessment stage, the level of $L$ will be between $1-3$, followed by $2-4$ for simulation stage and $3-5$ for the maintenance stage.

Table 1. ASDS domain severity (S) matrix

\begin{tabular}{cccccc}
\hline \multicolumn{5}{c}{ Severity (S) } \\
\hline \multirow{2}{*}{ Domain } & Low & Mild & Moderate & Severe & Very severe \\
& $(1)$ & $(2)$ & $(3)$ & $(4)$ & $(5)$ \\
\hline D1 & $65-53$ & $52-40$ & $39-27$ & $26-14$ & 13 \\
\hline D2 & $50-41$ & $40-31$ & $30-21$ & $20-11$ & 10 \\
\hline D3 & $40-33$ & $32-25$ & $24-17$ & $16-9$ & 8 \\
\hline D4 & $30-25$ & $24-19$ & $18-13$ & $12-7$ & 6 \\
\hline D5 & $20-17$ & $16-13$ & $12-9$ & $8-5$ & 4 \\
\hline D6 & $15-13$ & $12-10$ & $9-7$ & $6-4$ & 3
\end{tabular}

In the current practice, HIRARC only used for assessment of hazard and risk at the workplace and its activities. There was no clear evidence that it can be used and required for transport systems and operators (drivers) locally and internationally. However, with careful transformation and application of the matrix, it could create a better understanding of human factors and transportation issue. By strict implementation, it will eliminate, reduce and control the possibility for any accidents to occur. 


\subsection{Result}

A total of 694 students participate in this study. There were three categories of the age group, which 20-22 years old contributed to $61.7 \%$ of the total respondent. A majority of the respondents were females ( $n=547)$, followed by males $(n=147)$. A total of 416 respondents have a valid driving license followed by 278 respondents do not have a valid driving license. Only $32.6 \%$ of the respondent has witness's accident, and 19\% had experienced as a victim. Table 2 shows the minimum, maximum and mean value of scores from each domain of ASDS. The mean value from this score was used as a cut-off value to determine high and low-risk drivers. If the score falls correctly as the mean value; neither high nor low risk, medium (M) classification will be used. The increasing number of score represents a better attitude of the respondent and vice versa.

Table 2. Minimum, maximum and mean cut-off of high and low risk drivers for each domains.

\begin{tabular}{lccccccc}
\hline & \multicolumn{7}{c}{ Statistics } \\
\hline Mean & D1 & D2 & D3 & D4 & D5 & D6 & TOTAL \\
Minimum & 45 & 36 & 32 & 20 & 12 & 9 & 157 \\
Maximum & 13 & 15 & 16 & 6 & 4 & 3 & 94 \\
Definition & 65 & 50 & 40 & 30 & 20 & 15 & 220 \\
& $H<45>\mathrm{L}$ & $\mathrm{H}<36>\mathrm{L}$ & $\mathrm{H}<32>\mathrm{L}$ & $\mathrm{H}<20>\mathrm{L}$ & $\mathrm{H}<12>\mathrm{L}$ & $\mathrm{H}<9>\mathrm{L}$ & $\mathrm{H}<157>\mathrm{L}$
\end{tabular}

$\mathrm{H}=$ High, $\mathrm{L}=\mathrm{Low}, \mathrm{M}^{*}=$ Medium.

*If the score falls exactly as mean value, $M$ will be recorded.

Table 3 shows that $416(59.9 \%)$ respondent who participated in the survey at the maintenance stage followed by $278(40.1 \%)$ at the pre-assessment phase. Table 3 shows the 'demographic' data of three categories of ASDS risks level according to ASDS domain. The HIRARC likelihood value shows two increments from stage one to stage three of PreSiM model. That number later will be used to identify the final group score.

Table 3. Pre-assessment and maintenance group of PreSiM model, ASDS risk level according to six domains and HIRARC likelihood (L) score

PreSiM model stages

\begin{tabular}{|c|c|c|c|c|c|c|c|}
\hline \multirow[b]{3}{*}{$\begin{array}{l}\text { ASDS } \\
\text { Domain }\end{array}$} & \multirow[b]{3}{*}{ ASDS Risk level } & \multirow{2}{*}{\multicolumn{3}{|c|}{ Pre - pre-assessment $(n=278)$}} & \multirow{2}{*}{\multicolumn{3}{|c|}{$M$ - maintenance $(n=416)$}} \\
\hline & & & & & & & \\
\hline & & $\begin{array}{l}\text { HIRARC } \\
\text { likelihood } \\
\text { value }\end{array}$ & Frequency & $\begin{array}{l}\text { Per cent } \\
(\%)\end{array}$ & $\begin{array}{l}\text { HIRARC } \\
\text { likelihood } \\
\text { value }\end{array}$ & Frequency & $\begin{array}{l}\text { Per cent } \\
(\%)\end{array}$ \\
\hline \multirow{3}{*}{$\mathrm{D} 1$} & High risk & 3 & 128 & 46.0 & 5 & 205 & 49.3 \\
\hline & Medium risk & 2 & 7 & 2.5 & 4 & 15 & 3.6 \\
\hline & Low risk & 1 & 143 & 51.4 & 3 & 196 & 47.1 \\
\hline \multirow{3}{*}{$\mathrm{D} 2$} & High risk & 3 & 110 & 39.6 & 5 & 163 & 39.2 \\
\hline & Medium risk & 2 & 18 & 6.5 & 4 & 41 & 9.9 \\
\hline & Low risk & 1 & 150 & 54.0 & 3 & 212 & 51.0 \\
\hline \multirow{3}{*}{ D3 } & High risk & 3 & 103 & 37.1 & 5 & 124 & 29.8 \\
\hline & Medium risk & 2 & 34 & 12.2 & 4 & 45 & 10.8 \\
\hline & Low risk & 1 & 141 & 50.7 & 3 & 247 & 59.4 \\
\hline \multirow{3}{*}{ D4 } & High risk & 3 & 99 & 35.6 & 5 & 145 & 34.9 \\
\hline & Medium risk & 2 & 39 & 14.0 & 4 & 53 & 12.7 \\
\hline & Low risk & 1 & 140 & 50.4 & 3 & 218 & 52.4 \\
\hline \multirow{3}{*}{ D5 } & High risk & 3 & 105 & 37.8 & 5 & 158 & 38.0 \\
\hline & Medium risk & 2 & 63 & 22.7 & 4 & 64 & 15.4 \\
\hline & Low risk & 1 & 110 & 39.6 & 3 & 194 & 46.6 \\
\hline \multirow{3}{*}{ D6 } & High risk & 3 & 73 & 26.3 & 5 & 73 & 26.3 \\
\hline & Medium risk & 2 & 62 & 22.3 & 4 & 62 & 22.3 \\
\hline & Low risk & 1 & 143 & 51.4 & 3 & 143 & 51.4 \\
\hline
\end{tabular}

The group score only is used to make a lay comparison of HIRARC likelihood value between different stages of PreSiM model. It will not be able to determine the relative risk score. The relative risk score will only be able to compute on an individual basis. This paper does not show the details of the single score due to the high number of data. 


\subsection{Discussion}

The formula used for this transformation is simple and straight forward. The calculation can be easily be calculated using Microsoft Excel or SPSS. In term of field application, any employer could develop their database. From this database, the employer could develop proper and sensitive HIRARC driving program at the workplace. The individual assessment usually involved high risk or potentially high-risk drivers. The early screening program will enable us to understand the level of risky attitude that may contribute to the accident. Since the assessment was self-rated, caution should be made that honesty from each participant was important. Everybody should aware and agree that trustworthiness of their respond could contribute to a considerable difference in the whole HIRARC process. Even though it is understandable that human attitude is a complex phenomenon, ASDS was able to adequately reflect the relevant domain and seven road traffic offences as specified in the first schedule (section 2) of Malaysia Road Transport Act 1987. With systematic investigation, the ASDS found to be an appropriate assessment to provide information on road user's attitude especially among university students' such as seat belt compliance (Wan Ahmad Kamal, Masuri, Dahlan \& Md Isa (2015) where interestingly driving attitudes off campus is often reflected on campus (Hashim, Masuri, Md Isa, \& Ghazali (2020). This data transformation process provides a precious opportunity for further research related to human factors, transportation and $\mathrm{OSH}$. This also creates an opportunity for a multidisciplinary team from different background to work on future implementation.

\subsection{Conclusion}

The approach of using risk matrix to assess the level of severity attitude towards RTA among study participants was adequate in providing a key outcome of the measurement of risky driving behaviour. This approach offers a possible way of capturing the exact 'hazardous attitude' and level of its severity. By using different methods to assess the performance of the proposed tool, this research found that ASDS46 result transformation is valid and reliable in determining individual attitude status. The process of change from ASDS value into HIRARC matrix table shows promising result in assessing human factors in term hazard, risk and possible RTA control. This new scale will enable the Occupational Safety and Health $(\mathrm{OSH})$ team to evaluate the level of severity and action needed to prevent further injury.

In conclusion, HIRARC is not a task that is completed and then forgotten. The risk management process is ongoing. All potential risk and hazard identification should be appropriately documented even in the simplest of situations. Risk assessment should include a careful evaluation of both likelihood and severity. However, caution should be made where human components and occupational performance of drivers may change over time, and the risk controls are yet to be further analyzed. Control measures should conform to the recommendations of the hierarchy of control.

Finally from a professional point of view, this study provides opportunities to raise awareness of occupational therapy and other health professionals about the importance of specific and sensitive assessment to provide vital information in dealing with driving rehabilitation program. The demand for evidence-based intervention would increase health care and public awareness regarding the importance of scientific research and valid evidence. This new transformation highlights the occupational therapy professionals to create driving rehabilitation program training since it may help individuals who are at risk to change their attitude towards safe driving practices. This approach will provide support and increases public knowledge about the nature and causes of RTA potential risk and risk control relater to RTA. In the field of research, a formulation that found in this study may assist the occupational therapy to develop more sensitive and vigorous intervention program in future. This may not only helps occupational therapy to have standardized screening tools but also help to enhance the services in creating clear goals for driving rehabilitation program in the future. At the same time, occupational therapy can produce and contributes more research on human factors and transportation.

\section{Acknowledgements}

The highest appreciation goes to the Ministry of Higher Education Malaysia (MoHE), Royal Malaysia Police, Research Management Centre (RMC) Universiti Teknologi MARA (UiTM), CoRe Management Science, OPERA RIG, and all staff of the Faculty of Health Sciences UiTM Puncak Alam for continuous support in staff research and development. Thank you to our strategic partner, Ministry of Health, NIOSH Malaysia, DOSH and our future international collaborators: Tokyo University of Technology, Japan, Honam University, South Korea and Universiti Indonesia, Indonesia. Lastly, specially mentioned to our beloved friend and research team; Allahyarham Anniz Fazli Ibrahim Bajunid. This study was funded under the Fundamental Research Grant Scheme (FRGS) by MoHE - (600IRMI/FRGS 5/3 (126/2019).

\section{References}

Abang Mustaffa, D. N., Masuri, M. G., Dahlan, A., \& Md. Isa, K. A. (2015). The Intention in Speeding Behavior between Low and High Intended Young Driver's In Urban University. Paper presented at the Asia Pacific International Conference on Environment-Behaviour Studies, Barcelona School of Architecture (ETSAB), Universitat Politechnica De Catalunya (UPC), Barcelona, Spain.

Alert Driving Megazine, (2011). Human error accounts for $90 \%$ of road accidents. International News. Retrieved from http://www.alertdriving.com/home/fleet-alertmagazine/international/human-error-accounts-90-road-accidents

Bridger, R. S. (1995). Introduction to ergonomics. Singapore: McGraw-Hill International editions. 
Hashim, R., Masuri, M. G., Md Isa, K. A., \& Ghazali, A. R. (2020). Drivers' Attitudes on Campus Roads: A review. Environment-Behaviour Proceedings Journal, 5(13), 309-313. https://doi.org/10.21834/e-bpj.v5i13.1950

Masuri, M. G., Dahlan, A., Md Isa, K. A., \& Hashim, R. (2020). The Development and Validation of Pre-Driving Assessment: Attitude towards safe driving scale. Environment-Behaviour Proceedings Journal, 5(13), 337-342. https://doi.org/10.21834/e-bpj.v5i13.2060

Masuri, M. G., Mohd Asib, N. A., Dahlan, A., \& Md Isa, K. A. (2019). Human Factors and Attitude towards Safe Driving Scale among Young Adults in Malaysia. Environment-Behaviour Proceedings Journal, 4(11), 203-209. https://doi.org/10.21834/e-bpj.v4i11.1726

Masuri, M. G., Dahlan, A., Danis, A., \& Isa, K. A. M. (2014a, 24-26 February 2014). Public participation in shaping better Malaysian's road society in the future. Paper presented at the AicE-Bs2014Berlin Berlin, Germany.

Masuri, M. G., Dahlan, A., Danis, A., \& Isa, K. A. M. (2014b, 25-27 August 2014). Regeneration of Road System in the Urban Environment: Will Rehabilitation Components Orientate Road Users? Paper presented at the AcE-Bs2014Seoul, Chung-Ang University, Seoul, S. Korea.

Masuri, M. G., Dahlan, A., Danis, A., \& Md Isa, K. A. (2016). Attitude towards Safe Driving Scale (ASDS) As a Future Predictor in Determining a Young Adult Quality Of Life: Part I. Procedia - Social and Behavioral Sciences, 234, 390-397. doi:https://doi.org/10.1016/j.sbspro.2016.10.256

Masuri, M. G., Dahlan, A., Danis, A., \& Md Isa, K. A. (2017). Attitude towards Safe Driving Scale (ASDS-46) As a Future Predictor in Determining a Young Adult Quality Of Life: Part II. Environment-Behaviour Proceedings Journal 2(5) 363-368

Masuri, M. G., Dahlan, A., Md Isa, K. A., Danis, A., Natar, A. K. M., Thanapalan, C. K. K., .. Yusoff, M. N. M. (2014). The Use of Protection Motivation Theory (PMT) in developing Malaysian Driver's Attitude Evaluation. Paper presented at the CHUSER2014, Penang Malaysia in press.

Masuri, M. G., Md Isa, K. A., \& Mohd Tahir, M. P. (2012). Children, Youth and Road Environment: Road Traffic Accident. Procedia - Social and Behavioral Sciences, 38(0), 213-218.

Masuri, M. G., Md Isa, K. A., Mohd Tahir, M. P., Hassan, H. F., Hassan, Z., Jamhuri, F. Z., .. Noor, S. H. (2012). Behaviour Response among Health Sciences Students towards H1N1 Pandemic. Procedia - Social and Behavioral Sciences, 36(0), 77-86. doi:10.1016/j.sbspro.2012.03.009

Md Isa, K. A., Masuri, M. G., Abd Aziz, N. A., Md Isa, N. N., Hazali, N., Mohd Tahir, M. P., ... Hassan, H. F. (2012). Mobile Phone Usage Behaviour while Driving among Educated Young Adults in the Urban University. Procedia - Social and Behavioral Sciences, 36(0), 414-420.

Third African road safety congress. (1997). Financing of road safety actions. Paper presented at the Third African road safety congress Pretoria, South Africa. http://www.worldbank.org/transport/publicat/b28.pdf

Wan Ahmad Kamal, W. N. H., Masuri, M. G., Dahlan, A., \& Md Isa, K. A. (2015). Seat Belt Compliance and Quality of Life among Educated Young Adults in an Urban University. Procedia - Social and Behavioral Sciences, 202, 442-447. doi:http://dx.doi.org/10.1016/j.sbspro.2015.08.249 